\title{
Agregado reciclado: um novo material da construção civil
}

\author{
Leandro Moreno de Souza', Cleber Decarli de Assis², Silvia Barroso Gomes Souto 3 \\ 'Acadêmico do Curso de Engenharia Civil do Instituto Tocantinense Presidente Antônio Carlos,TO, Brasil \\ ${ }^{2}$ Professor do Curso de Engenharia Civil do Instituto Tocantinense Presidente Antônio Carlos,TO, Brasil
}

\section{Resumo}

O ramo da construção civil consome durante o seu processo uma grande quantidade de material, o que de certa forma acaba gerando em escalas grandes os Resíduos da Construção e Demolição que são mais conhecidos como RCD's, resíduos que em certos grandes centros alcançam um número de proporções preocupantes, podendo em diversos depósitos de resíduos a sua participação sendo de até $50 \%$ do total que é disposto no local pré-determinado. Com esses dados pode-se entender que a necessidade em se pensar na reutilização desses resíduos acaba sendo extremamente importante tanto para o âmbito ambiental em que se aliviam os impactos ocasionados pele mesmo ao meio ambiente, assim como em caráter econômico. Em diversos estudos em que se analisa a viabilidade do reaproveitamento dos resíduos da construção, se observa que não há uma garantia em relação aos parâmetros de que garantem segurança quando o mesmo utilizado em artefatos de concreto. Com isso, este trabalho tem como objetivo determinar os parâmetros de resistência de blocos de concreto e concreto, com a utilização de agregados cerâmicos e agregados de concreto considerado os brancos.

Palavras-chave: resíduos da construção e demolição; reciclagem; agregados reciclados; concreto reciclado.

\begin{abstract}
The civil construction sector consumes during its process a large amount of material, which somehow ends up generating great scales Waste Construction and Demolition better known as RCD 's waste in certain major centers reach a number of ratios concern and may in various waste deposits its share being $50 \%$ of the total which is arranged in a predetermined location. With these data one can understand the need to think about the reuse of this waste ends up being extremely important for both the environmental context in which they alleviate the impacts caused even skin to the environment, as well as economic character. In several studies that examines the feasibility of reuse of construction waste, it is observed that there is no warranty in relation to the parameters that ensure safety when used in concrete artifacts . Therefore, this study aims to determine the strength parameters of concrete blocks and concrete, with the use of ceramic aggregates and concrete aggregate considered whites
\end{abstract}

Keywords: construction and demolition waste, recycling, recycled aggregates, recycled concrete 


\section{GENERALIDADES}

No que diz respeito aos Resíduos da Construção e Demolição - RCD encontrados tanto no processo de fabricação, como na execução de obras na indústria da construção civil, as leis encontradas que regulamentam sobre a disposição final desejada acabam sendo de certa forma muito exigentes sobre o padrão de qualidade satisfatório (GONÇALVES, 2001).

Segundo Toaldo (1993), certos países de primeiro escalão no qual as leis e normas acabam sendo muito rígidas citando assim o exemplo do Japão, onde deve haver sempre um programa que inclua dentre o cronograma e orçamento uma disposição final adequada para os resíduos gerados.

Deve-se levar em consideração que no ramo da construção civil a utilização de matérias primas para a confecção de um empreendimento, tem origem em grandes atividades de extração em jazidas sendo elas de areia, argila ou material pétreo, na qual requer um cuidado ambiental uma vez que os impactos são notáveis e as retiradas descontroladas em longo prazo, implicando em escassez do material procurado, assim a utilização de um método renovável para se aprofundar além de se tornar sustentável podendo elevar a qualidade do seu empreendimento, pode-se relevar mais barato do que os métodos convencionais (HOOD, 2006).

\section{I.I ComposiçÃo Dos Resíduos}

A necessidade de se conhecer os resíduos envolvidos durante o processo, assim como aqueles provenientes de materiais de demolição levou a uma pesquisa aprofundada como em países de primeiro mundo, com isso é possível identificar na comunidade europeia, o valor estimado fica em torno de 170 milhões de toneladas/ano e com isso fornece dados percentuais, que pode ser explicado de acordo com o gráfico a seguir mostrando a participação do concreto com $41 \%$, sendo os tijolos e blocos responsáveis por $40 \%$, os materiais asfálticos correspondem $12 \%$, já os materiais cerâmicos ficam com $7 \%$ do total (VAN ACKER, 1996).

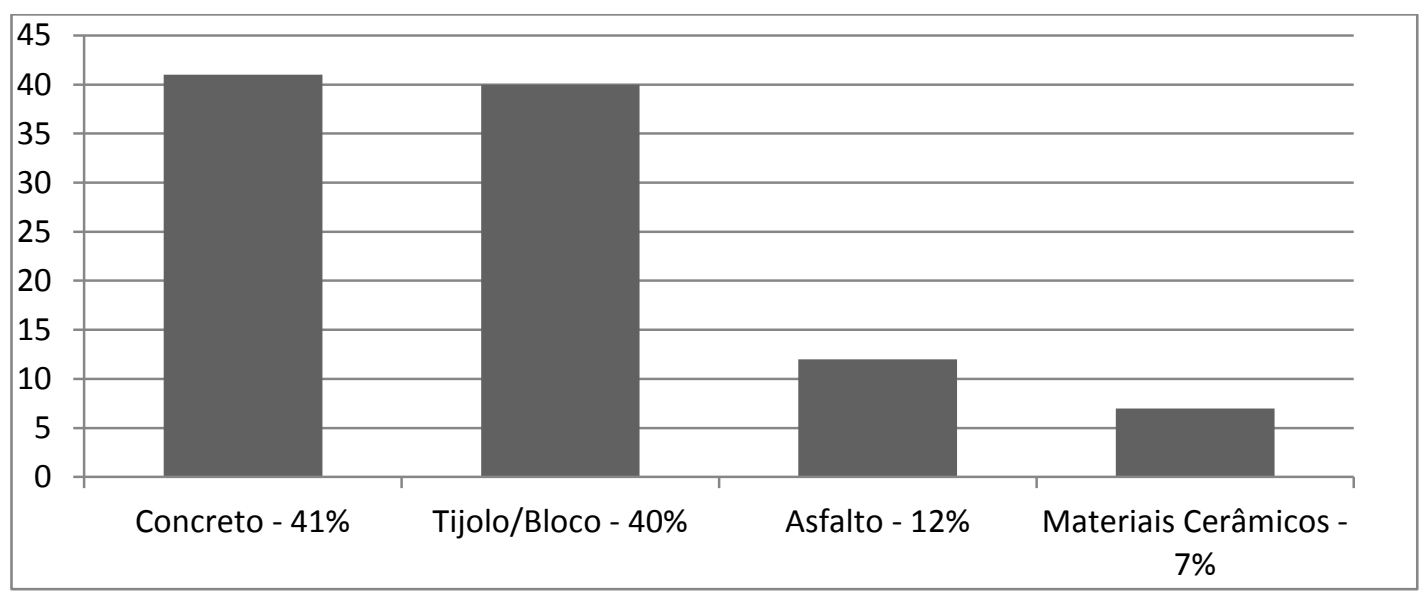

Figura 2.1 - Porcentagem de alguns resíduos da construção civil na comunidade europeia Fonte: VAN ACKER, (1996)

\section{I.2 CLASSIFICAÇÃo Dos Resíduos}

Levando em consideração, a Resolução CONAMA n 357/02 (2002), classifica e denomina os resíduos em quatro categorias, sendo a classe $\mathrm{A}$, classe $\mathrm{B}$, classe $\mathrm{C}$ e classe $\mathrm{D}$.

$\mathrm{Na}$ classe A é o grupo em que se incluem todos os resíduos que posteriormente podem ser usados como agregados, sendo eles originados de material reciclável como concreto, alvenaria,

Já na classe B, na sua origem ficam estabelecidos por materiais recicláveis para outro destino sendo citados os plásticos, papéis, metais, madeiras;

$\mathrm{Na}$ classe $\mathrm{C}$ são os resíduos sem tecnologia ou até mesmo com pouca viabilidade econômica para reciclagem que acabam sendo descartados;

Em relação à classe D são os materiais oriundos do processo da construção mais perigosos 
como: tintas, solventes ou óleo, que são contaminados;

Assim de acordo com a Norma Brasileira Regulamentadora (NBR) os devidos resíduos são enquadrados em classes, que estão explicadas na NBR 10004 (2004):

- Resíduos Classe I - Perigosos

- Resíduos Classe II - Não perigosos

- $\quad$ Resíduos Classe II A - Não inertes

- $\quad$ Resíduos Classe II B - Inertes

Com isso Pinto (1999) tentando identificar um melhor entendimento sobre a origem da construção estipulou que no Brasil a quantidade de RCD que é gerado proveniente da atividade de manutenção e reforma, assim como as de demolição são responsáveis por uma margem que varia de 42 a $80 \%$.

\section{I.3 Origem Dos Resíduos Da Construção e Demolição}

Referente aos processos construtivos fica claro que os resíduos acabam sendo gerados devido a vários ciclos na construção, como (AGOPYAN et al., 1998):

- Processo de construção

- Processo de manutenção e reformas;

- Fase de demolição de edifícios;

De acordo com a fase de construção da obra citam-se as perdas que de certa forma é decorrente dos processos construtivos, podendo identificar nessa fase que a maioria das determinadas perdas acaba sendo incorporadas nas fases seguintes como é o caso de concretos ou até mesmo argamassas de revestimento (AGOPYAN et al.1998).

Outro método que resulta em perdas e resíduos provenientes da construção civil é citado por John (2000), dizendo que as perdas através de manutenção ficam claras em casos de correção de atividades patológicas no final da vida útil de uma estrutura, muito encontrado também em casos de reformas e atividades que buscam uma mudança, visando assim à modernização da edificação que neste caso é inevitável a pratica de demolição do empreendimento.

$\mathrm{Na}$ etapa da demolição da construção os resíduos são provenientes de problemas que se estime um longo período, portanto a redução dos materiais desse processo acaba sendo um pouco difícil prever, uma vez que a vida útil de um empreendimento pode depender de vários fatores como processos químicos, físicos ou forças mecânicas, porem de certa forma esta fase acaba sendo inesperada, uma vez que os estudos que avaliem a durabilidade das edificações são pouco estudados (AGOPYAN et al., 1998).

\section{I.4 Agregados ReCicLados}

Observando os agregados com característica reciclável de concreto, no qual se diz possuir em seu teor, uma porcentagem de 40 a $50 \%$ do seu volume de argamassa, assim podendo se analisar um mau desempenho do concreto quando o mesmo é produzido com a reutilização do agregado reciclado (CABRAL, 2007). Ainda de acordo com Hood (2006), cita fatores importantes em relação à utilização do agregado sendo ele graúdo ou miúdo.

No caso de agregados graúdos o mesmo analisou que a sua utilização apresenta resultados satisfatórios, no que se diz respeito ao fator água cimento sendo o valor bastante baixo, podendo apresentar concreto com características mais densas, já a sua utilização como agregado graúdo, ficou claro a sua deficiência principalmente referente à resistência a compressão, a abrasão e a permeabilidade (HOOD, 2006).

Deve-se sempre salientar quando se faz a aplicação de materiais, de acordo com sua composição específica, uma vez que em casos de materiais com porosidade elevada proveniente de argamassa, concretos estruturais e cerâmicas vermelhas podem apresentar propriedades mecânicas consideradas menores, afetando de maneira significante a resistência dos agregados e podendo ser bastante percolados pela água devido a sua absorção (AGOPYAN et al., 1998). 


\section{I.5 AplicaÇÃo dos agregados ReCiclados}

Visando a melhor utilização dos agregados reciclados como material de construção e consequentemente a sua possibilidade em se adquirir produtos no qual sua composição os agregados podem ser incluídos, muitas são as pesquisas que buscam essa tal viabilidade dos RCD's em um meio mais técnico como é o caso de grandes rodovias americanas, em que podemos citar a de Michigan - EUA no qual seu histórico deixa claro que durante o seu processo construtivo a utilização de agregado reciclado de origem da própria seção da pista foi de suma importância tornando assim a primeira rodovia com grandes dimensões a utilizar matéria prima reciclável durante a fase de construção (MEHTA, 1994).

No caso de argamassas Levy (1997) cita que se deve haver um tratamento adequado dos agregados uma vez que pode se constar no seu produto final características indesejáveis que aparentemente são apresentadas devido às más propriedades do agregado reciclado.

Em trabalho realizado por Ângulo (2000), o mesmo afirma que em uma pesquisa de campo, na qual a argamassa com produtos reciclados foram testadas nas obras em meio a opiniões dos pedreiros, que avaliaram de forma positiva o material no qual as argamassas recicladas apesentando uma agradável aceitação.

Quando se pretende confeccionar blocos de concreto principalmente com a utilização de agregado reciclado deve-se analisar pontos bastante relevante como é o caso das características necessárias que se deve atender, quando os mesmos forem submetidos às solicitações de serviço, podemos citar características como a taxa de resistência a compressão onde é observando quando os blocos são introduzidos como material de pavimentação, assim como analisar as taxas de absorção de água e abrasão. $\mathrm{Na}$ utilização dos blocos como vedação, os principais dados que serão avaliados devem ser tanto a compressão, além da absorção de agua medindo consequentemente as suas taxas (HOOD, 2006).

\section{I.6 Propriedades dos agregados ReCICLAdos}

\section{I.6.I Massa especifica}

A massa especifica de um agregado está ligado e consequentemente é um resultado que depende da porosidade. Comprovado por Ângulo (2000) em estudos realizados na usina de Santo André-SP, observou-se uma considerável variabilidade, quando os agregados que apresentam alta taxa de absorção de água, são os mesmo que tendem a apresentar massa especifica com valores menores.

Porém o fato dos agregados apresentarem massa especifica com valores menores que os naturais podem ser usados de maneira satisfatória na confecção de artefatos de concreto, uma vez que o fato de exibir uma massa especifica menor, as peças terão seu peso próprio bastante inferior quando comparado com agregados naturais, outra característica bastante relevante seria a esbeltes de peças com seções bastante reduzidas, no qual pode significar uma considerável redução econômica do empreendimento (CABRAL, 2007).

\section{I.6.2 Trabalhabilidade}

Segundo Cabral (2007), quando se compara os agregados reciclados com de origem natural observa-se que a sua trabalhabilidade é afetada chegando a apresentar resultados menores, o que pode ser explicado pelo fato de que os agregados reciclados são considerados mais secos que os normais, ocasionando uma maior absorção de água do que o normal, fazendo com que o resultado final apresente um material com uma mistura mais seca pelo fato dos agregados retirarem a agua do processo que seria usado no cimento o que provoca uma menor trabalhabilidade do conjunto.

$\mathrm{O}$ mesmo autor destaca que um dos fatores que podem explicar essas características apresentadas nos materiais com agregado reciclado é o fato da britagem do processo que pode causar uma formação de agregados com extremidades angulares, fator que não é característico em materiais naturais que são arredondados e com uma superfície lisa.

\section{I.6.3 Resistências à compressão}

Segundo Hansen (1992), em testes realizados com a substituição de agregado natural por reciclado, alcançou grandes resultados em que pode-se considerar que o concreto quando submetido a forças de compressão apresentam uma melhoria da resistência em até 33\%.

Porém dados demonstrados por Cabral (2007), a resistência de concretos naturais chega a superar os produzidos com matéria prima reciclável em até $45 \%$, então pode-se dizer que em 
relação a esta diferença de dados esta relacionado ao processo de britagem, assim como a origem do material, além da qualidade do material principalmente o cimento, pois originar o surgimento de vazios que consequentemente comprometem a sua resistência.

Carrijo (2005) determinou em um processo de análise de resistência à compressão em concretos com agregados reciclados, em que os resultados podem ser definidos de acordo com a aplicação e medição de forças e anotando os dados referentes ao desempenho do concreto e avaliando como o mesmo está comportando com a aplicação das forças. Com isso ao se identificar artefatos de concerto que rompem e consequentemente se desagregam após a ruptura do corpo de prova, pode se dizer que os mesmos têm valores inferiores aos do que é estabelecido para o concreto propriamente dito com agregados naturais.

\section{I.6.4 Resistências à abrasão}

Quando se cita a abrasão dos materiais, se diz ao respeito ao que podemos falar como sendo a capacidade do agregado em se fragmentar quando o mesmo é colocado em contato com outro material (CARRIJO, 2005).

Leite (2001) considera que os agregados reciclados apresentam uma resistência ao contato e impacto menor, gerando um maior desgaste por abrasão quando comparado aos naturais. Os ensaios de abrasão para que chegue a sua determinação utiliza-se através da metodologia mais usual que é através do ensaio americano Los Angeles que no mesmo ensaio pode combinar tanto abrasão como também atrito, pois a análise mostra boa eficiência com os resultados relacionados ao desgaste real dos agregados além de apresentar dados como a resistência à compressão e a resistência à flexão do concreto confeccionado com agregado proveniente de resíduos da construção civil em sua composição, podendo citar resultados em que a perda do agregado reciclado pela abrasão foi maior em uma diferença de 3 vezes quando equiparado com agregados naturais, sendo que os resultados independiam da granulometria dos materiais (TENORIO, 2007).

\section{CONSIDERAÇÕES FINAIS}

Observou-se que a geração de resíduos acontece em grande escala, principalmente quando são oriundos de grandes demolições e processo de reforma. Com isso perante dos dados analisados os agregados reciclados da construção e demolição da construção civil apresentaram uma boa solução quando são submetidos ao processo de reutilização, uma vez que desafogam a exploração indiscriminada dos recursos naturais, porém deve-se resguardar a utilização em artefatos de concreto de caráter estrutural, uma vez que parâmetros de resistência apontaram uma deficiência com a utilização de agregados reciclados devido a sua origem sendo elas tanto cerâmico, como de concreto e argamassas, além também da edificação que o foi retirado, assim como o sua devida triagem e tratamento.

Em grandes centros os resíduos podem se tornar uma excelente alternativa, devido à falta de recurso natural, com isso a introdução dos agregados em algumas construções podem se tornar atraente, tanto economicamente, além de fatores ambientais que dependendo do uso pode qualificar o empreendimento em parâmetros ambientais, concedendo a mesma alguns certificados.

\section{REFERÊNCIAS}

ANGULO, S.C. Variabilidade de agregados graúdos de resíduos de construção e demolição reciclados. São Paulo, 2000. 155p. Dissertação (Mestrado) - Escola Politécnica, Universidade de São Paulo.

AGOPYAN.et.al . Reciclagem de resíduos da construção. Departamento de Engenharia de Construção Civil, Escola Politécnica da USP 1998.

CABRAL, A. E. B.. Modelagem de propriedades mecânicas e de durabilidade de concretos produzidos com agregados reciclados, considerando-se a variabilidade da composição do rcd. Tese apresentada á escola de engenharia de são carlos, como parte dos requisitos para obtenção do titulo de doutor em ciência da engenharia ambiental (2007) 
CARRIJO, P. M. Análise da influência da massa específica de agregados graúdos provenientes de resíduos de construção e demolição no desempenho mecânico do concreto. São Paulo: USP, 2005. Dissertação (Mestrado em Engenharia Civil), Escola Politécnica da USP, Universidade de São Paulo, 2005

CONSELHO NACIONAL DO MEIO AMBIENTE. Dá diretrizes gerais para uso e implementação da Avaliação de Impacto Ambiental. Resolução CONAMA n 001. Brasília, 1986. Dispõe sobre gestão dos resíduos da construção civil. Resolução CONAMA nº 307. Brasília, 2002

GONÇALVES R. D. C. agregados reciclados de resíduos de concreto - um novo material para dosagens estruturais. dissertação mestrado. escola politécnica da Universidade de São Paulo. Departamento de Engenharia de Construção Civil.(2001)

JOHN, V. M. Reciclagem de resíduos na construção civil: Contribuição para metodologia de pesquisa e desenvolvimento. São Paulo, 2000. 113p. Tese (Livre Docência) - Escola Politécnica da Universidade de São Paulo. Departamento de Engenharia de Construção Civil.

LEITE, M. B. avaliaçao de propriedades mecanicas de concretos produzidos com agregados reciclados de residuos de construção e demolição. porto alegre. tese de doutorado em engenharia civil, programa de pos graduação em engenharia civil, universidade federal do rio grande do sul, 2001

MEHTA, P. K.; MONTEIRO, P. J. M. Concreto: estruturas, propriedades e materiais. São Paulo, Ed. PINI, 1994.

NBR 10004 - Resíduos Sólidos. Rio de Janeiro, 2004

TOALDO, E.. Para não virar pó. Construção, São Paulo n.2348, p.10,fevereiro. (1993)

VAN ACKER, A . (1996). Recycling of concrete at precast concrete plant. BIBM. Paris. p.55-67, juliet.

LEVY, S.M. Reciclagem de entulho de construção civil para utilização como agregado de argamassas e concreto. 145p. Dissertação (Mestrado) - Escola Politécnica, Universidade de São Paulo, São Paulo, 1997.

Hansen, T. Recycling of demolished concrete and masonry. London: E \& FN SPON, Rilem report 6, 1992.

HOOD, S. R. D. S. Analise da viabilidade técnica da utilização de resíduos de construção e demolição como agregado miúdo reciclado na confecção de blocos de concreto para pavimentação. Universidade Federal Do Rio Grande Do Sul.Engenharia. Programa de Pós - Graduação em Engenharia Civil. (2006)

TENÓRIO, J. J. L. Avaliação de propriedades do concreto produzido com agregados reciclados de resíduos de construção e demolição visando aplicações estruturais. Dissertação apresentada ao Programa de Pós - Graduação em Engenharia Civil da Universidade Federal de Alagoas como requisito parcial para obtenção do título de Mestre em Engenharia Civil. 2007 